\title{
Experimental Testing on an Air-Cooled Condenser Motor, Gearbox and Fan
}

\author{
C.J. van Rensburg ${ }^{1, *}$, M.P. Venter ${ }^{1, * *}$, and D.N.J. Els ${ }^{1, * * *}$ \\ ${ }^{1}$ Department of Mechanical and Mechatronic Engineering, Stellenbosch University
}

\begin{abstract}
The majority of South Africa's electricity is generated from coalfired power stations. After expansion through the turbine stage the heated steam is condensed by air-cooled condensors (ACCs). In water scarce areas air-cooled condensers are used to reject heat by means of convection through an array of fans that force air over the heated steam tubes positioned in a A-frame structure above the fan. The ACC system consists of an induction motor, two-stage gear reducer and an axial fan. For this research, the rotational velocity of the gearbox's output shaft is measured as well as the bending and torsional strain experienced during different stages of operation. A proximity sensor and various sets of strain gauges are used to record the measurements respectively. Testing was conducted at three different sites that utilize different control methods for the induction motors. The purpose of testing at different sites was to evaluate the effectiveness of each start-up control system and its application inside an ACC. The results obtained in each of the three cases are quite clear that any motor controller is beneficial to the overall system simply due to the reduced inrush current and torque peaks.
\end{abstract}

\section{Introduction}

South Africa has large coal reserves situated in the North-Eastern regions of the country. It is because of this reason that the majority of the country's electricity is generated by coalfired power stations in those areas. Unfortunately, these regions are considered water scarce and cannot sustain the traditional wet cooling tower power plants. To avoid this problem, the latest power plants in the region use forced air to reject heat into the atmosphere through air-cooled condensers.

The induction motors used in ACCs typically have a rated output of $\sim 250 \mathrm{~kW}$. Usually within the first $5 \mathrm{~s}$ of start-up, the torque peaks exerted on the gearbox by the induction motor can reach up to four times the rated torque of the gearbox, which over a prolonged period of frequent start-ups can damage the gearbox and lead to subsequent failure thereof.

An ACC system consists of the induction motor, a gearbox and axial fan supported by a walk bridge. The method of starting an induction motor is important to consider as this can significantly reduce the start-up torque peak [7]. The three starting methods that are investigated here are: direct-online (DOL), variable frequency drive (VFD) and a soft-starter.

\footnotetext{
*e-mail: 19840918@sun.ac.za

**e-mail: mpventer@sun.ac.za

***e-mail: dnjels@sun.ac.za
} 
In the case of a DOL connection, the motor is directly connected to the power grid and is also the fastest starting method, since no motor controller is used. A VFD reduces the start-up torque by altering the magnitude and frequency of the voltage supplied to the motor. The soft-starter reduces the voltage supplied to the motor and subsequently limiting the peak current and torque.

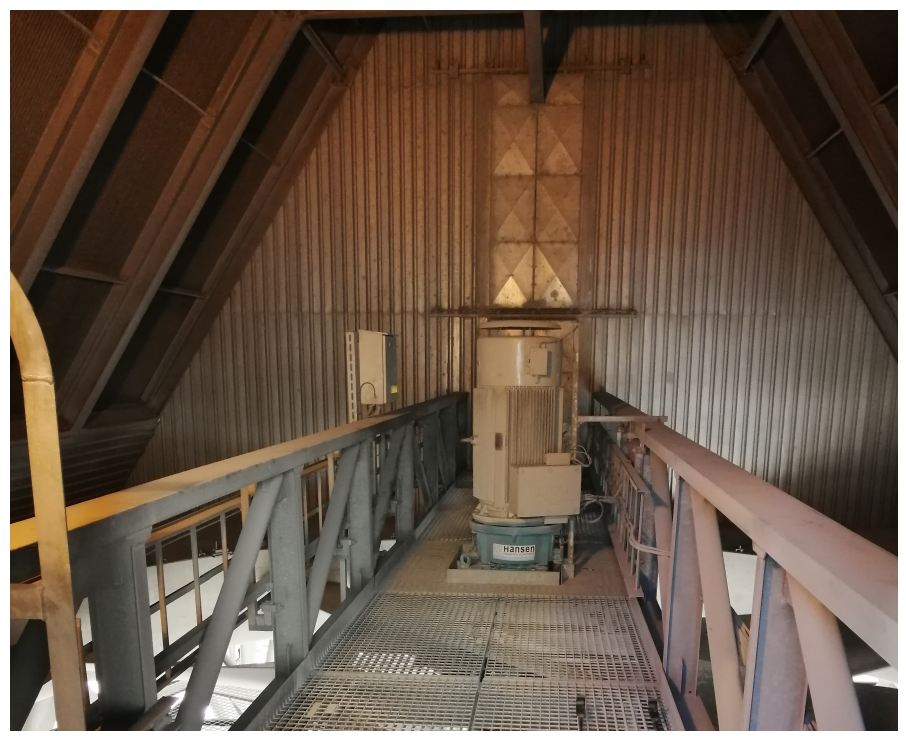

Figure 1: ACC cooling tower motor and gearbox installation

The most common areas of gearbox failure are found to be the bearings and gear tooth fatigue damage [4]. Measurements on both shafts of the gearbox was taken by [1] to relate the input torsion and bending strain to the output side of the gearbox.

Further contributions to shaft vibration and bearing wear is caused by the aerodynamic loading experienced by the fan. The most probable causes for unbalanced aerodynamic loads are: dynamically unbalanced blades (1); variances in attack angle of fan blades (2); and distorted inlet airflow conditions (3). The close proximity of the support bridge to the fan also affects airflow conditions downstream of the fan [2].

The aim for this research was to determine the most suitable motor controller by comparing the difference in start-up torque peaks and start-up time. The same type of measurements were conducted at three different test sites. Each test site is installed with one of the aforementioned motor starting controllers, a two-stage gearbox $(\sim 10: 1)$ and a axial fan with a diameter of $\sim 10.36 \mathrm{~m}$.

\section{Induction Motor Control Methods}

\subsection{Direct on Line}

For this starting method, no controller is implemented and the motor terminals are connected to a three-phase power supply. The motor terminals can be connected in either the star or delta configurations shown in Figure 2 with the differences between the two connections being the line and phase voltages and currents. 


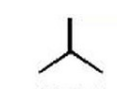

STAR

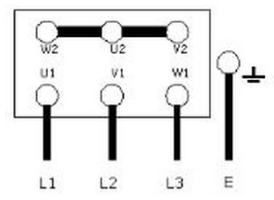

$\triangle$

DELTA

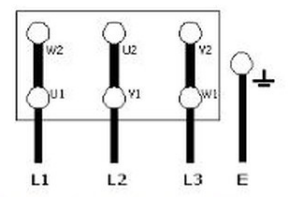

Figure 2: Three phase star \& delta connections for induction motor terminals

\subsection{Variable Frequency Drive}

The MinWaterCSP facility constructed at Stellenbosch University has a VFD installed that works in conjunction with a programmable logic controller (PLC) to determine the start-up characteristics of the motor. For any testing purposes, the motor speed is set on the VFD and the motor is accelerated to the set speed.

The advantage of this VFD is that the motor speed can be changed while the motor is running. The time accelerating the motor from standstill to full speed varies depending on the power grid the VFD is connected to. This is illustrated in Section 4.1 where the startup algorithm uses the voltage available to start the motor and the set speed to determine the start-up time. The size of the axial fan installed and power grid voltage available at the MinWaterCSP site makes it difficult to compare the startup time of the VFD against the other test sites. Figure 3 below illustrates the VFD's internal circuit diagram installed at [3].

The VFD receives three-phase alternating current $(\mathrm{AC})$ power from the grid and rectifies this into a direct current (DC) component. The DC component of the power supply contains ripples which are smoothed in the DC bus circuit of the VFD. Finally, a series of insulatedgate bipolar transistor (IGBT) switches convert the DC power back to AC before reaching the motor terminals. The VFD used at the MinWaterCSP plant is the CFW701 model from WEG.

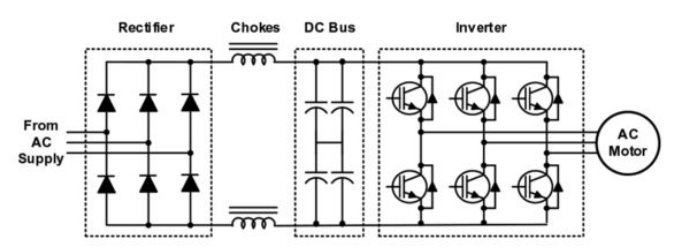

Figure 3: Internal circuit diagram of a VFD

\subsection{Soft-Starter}

A soft-starter motor controller is the cheaper alternative to install compared to the VFD, but only offers control of the start and stop phases of the induction motor. Once the motor reaches its rated speed, the soft-starter is bypassed (internally or externally) through a series of circuit breakers. There are two types of soft-starters available: IGBT- or thyristor-based. The soft-starter installed at power station II is thyristor-based. Referring to Figure 4, there are 
three pairs of thyristors connected in the anti-parallel configuration; one for the positive and negative half of each cycleof the supply voltage. The soft-starter controls the voltage supplied to the motor by only conducting for a short period of time based on gate pulses supplied to the thyristors or IGBT switches.

Figure 5 depicts an example of how the voltage supplied to the motor is increased during start-up and controlled by the firing angle of the thyristors. At start-up the angle is at a maximum to allow minimum voltage to the motor and gradually increase over time, allowing a larger part of the sinusoidal voltage to pass through.

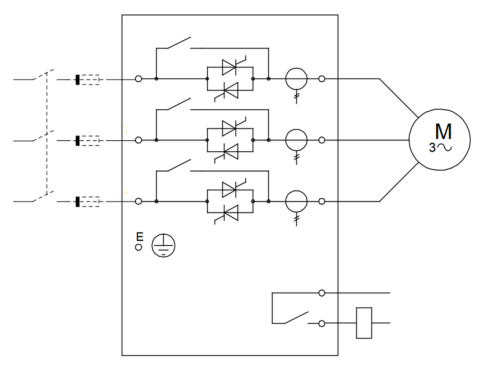

Figure 4: Soft-Starter internal circuit diagram

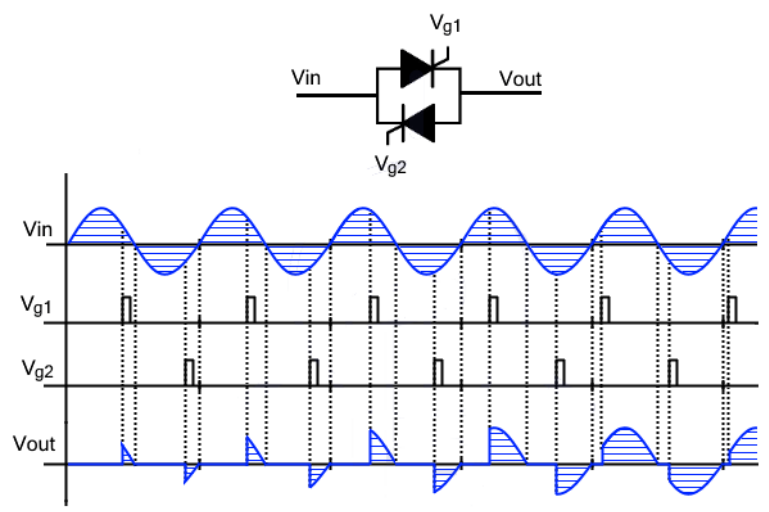

Figure 5: Start-up voltage increase of soft-starter

\section{Experimental Design}

There are three types of measurements of interest on the ACC motor \& gearbox for this research: speed measurement of gearbox output shaft (1); bending strain on the gearbox output shaft(2); and the torsional strain experienced by the gearbox output shaft (3). All measurements are synchronized by a QuantumX MX1601B module. 


\subsection{Speed Measurement}

The gearbox's low-speed shaft angular velocity can be determined using an optical or proximity sensor. To eliminate the effect of changing light conditions, an inductive proximity sensor was selected for this particular application. This type of sensor detects the presence of metallic objects close to the sensing surface. A wheel with 60 teeth was designed and fitted around the gearbox shaft for the proximity sensor to detect.

Figure 6 illustrates the final solution implemented for measuring the gearbox's shaft speed at all the test sites. This was the most effective solution given the physical constraints presented by the support platform of the motor and gearbox. Surface imperfections on the shaft's surface and manufacturing defects of the toothed wheel's parts, made it difficult to accurately align the two half discs. The vertically aligned sensor is used for a single pickup point whereas the horizontal sensor measures the frequency of the passing teeth. The two sensors are used to confirm the shaft speed.

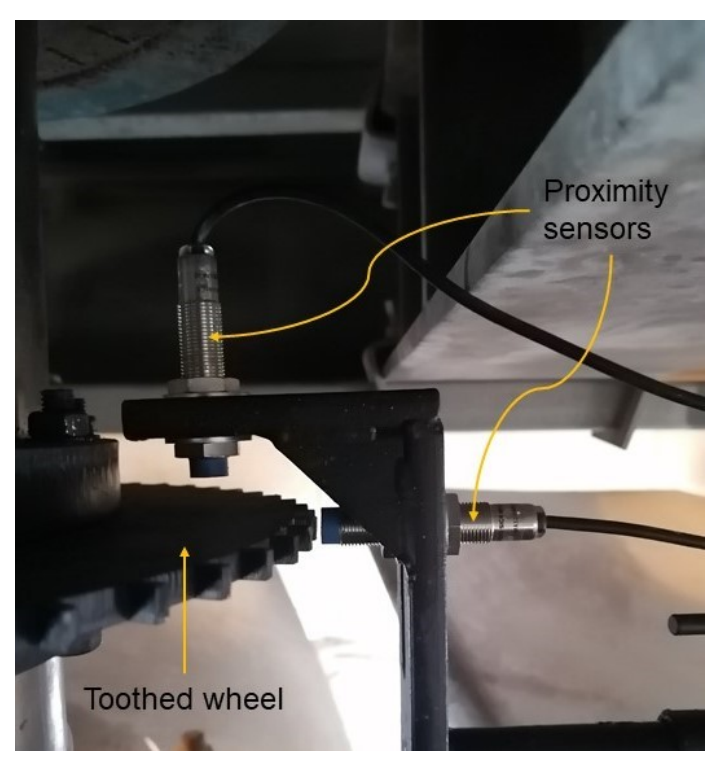

Figure 6: Toothed wheel installation with proximity sensors

\subsection{Bending Strain Measurement}

At start-up, the gearbox output shaft undergoes a transient bending phase whereafter it oscillates around a constant value. The circumferential positioning of the strain gauges doesn't affect the readings, but the distance away from the gearbox bearing along the length of the shaft does. To measure the bending strain, two sets of strain gauges (each gauge of $350 \Omega$ ) are positioned $180^{\circ}$ opposite each other.

Figure $7 \mathrm{~b}$ illustrates a half-bridge configuration foil. Two half-bridges are then connected to form a full-bridge configuration and complete the Wheatstone bridge for maximum sensitivity. On one side of the shaft, Figure $7 \mathrm{~b}$ would represent $R_{1}$ and $R_{3}$ in Figure $7 \mathrm{a}$ on the left. The two full-bridge configurations are positioned $90^{\circ}$ apart from each other and from Figure 8 it is possible to calculate the absolute bending moment of the shaft. 
The strain gauges are connected to a wireless V-Link 200 node from LORD MicroStrain that transmits data to a base station receiver (WSDA-Base-101-LXRS). A shunt calibration was performed from within the software before any readings were taken. The bending moment experienced in the shaft at the position of the strain gauges is then calculated using Equation 1:

$$
\sigma_{\text {shaft }}=\frac{\pi}{4} \cdot E \cdot \epsilon \cdot R^{3}
$$

where,

- $R$ is the shaft radius in $[\mathrm{m}]$

- $\epsilon$ is the strain measured in $\left[\frac{m}{m}\right]$

- $E$ is the shaft material's Young's modulus in [Pa]

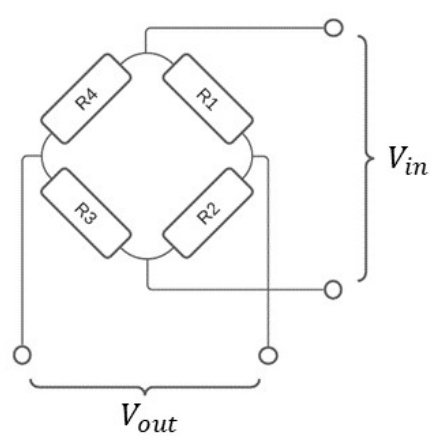

(a) Wheatstone bridge

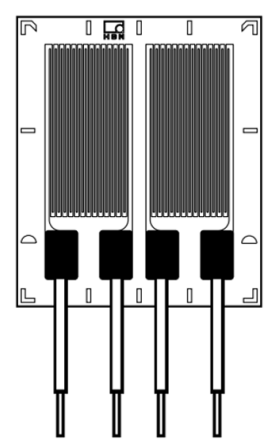

(b) Half-bridge strain gauge configuration

Figure 7: Bending strain gauge setup

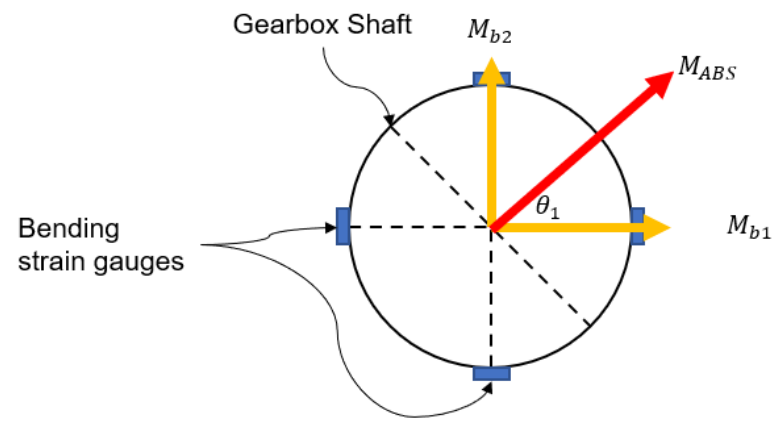

Figure 8: Bending strain gauges shaft positioning 


\subsection{Torsional Strain Measurement}

Shaft torsion is measured at the same position on the shaft as the bending strain. Figure 9 illustrates how the strain guage foil accomodates two $350 \Omega$ strain gauges that are $90^{\circ}$ apart from each other. Similar to the bending strain gauges, a shunt calibration is also performed before readings were taken. In the shunt calibration process, the wireless node uses an internal precision resistor to load part of the sensor bridge while the sensor remains unloaded. The setup shown in Figure 9 represents again a half-bridge configuration.

Once more, two half-bridges are wired together $180^{\circ}$ around the shaft to form a full-bridge configuration. Another advantage of using this configuration is it does not require internal circuit completion which is not available with the QuantumX MX1601B module used. From the measured torsional strain, the torque experienced by the shaft can be calculated using Equation 2.

$$
\tau_{\text {shaft }}=\frac{\pi E R^{3}}{2(1+v)} \cdot \epsilon
$$

where,

- $R$ is the shaft radius in $[\mathrm{m}]$

- $\epsilon$ is the strain measured in $\left[\frac{m}{m}\right]$

- $E$ is the shaft material's Young's modulus in [Pa]

- $v$ is the Poisson's ratio of the shaft material

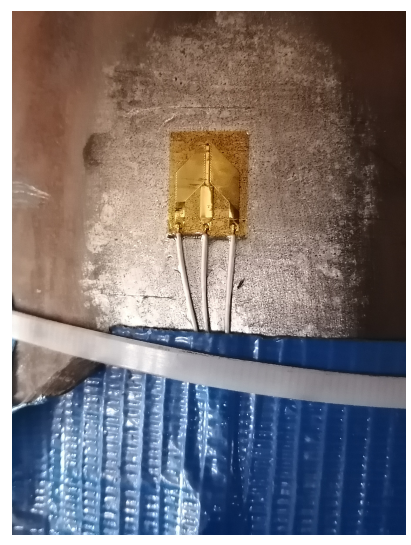

Figure 9: Torsional half-bridge strain gauge foil

\section{Results}

\subsection{MinWaterCSP Facility}

During the first $5 \mathrm{~s}$ of start-up, there are five clear peaks in the recorded shaft torsion as the VFD accelerates the motor (see Figure 10a). A possible cause for this is the control algorithm implemented in the PLC that controls the VFD according to the load on the motor. Figure 10b illustrates the sudden decrease of shaft torsion during the stoppage period of the induction 
motor. Figures 10a and 10b illustrates the angular velocity of the gearbox output shaft just before it reaches the set speed and deceleration of the shaft after motor shutdown. The measured angular velocity for both periods of opertation are fitted with a smoothing spline function implemented in MATLAB R2020b. The reason for the values of the smoothing parameters are to fit the measured data as accurately as possible. Figure 12 illustrates the bending moments calculated for the gearbox low-speed shaft for a $90 \mathrm{~s}$ period at steady-state. These circumferential position of the strain gauges measuring bending strain is $45^{\circ}$ rather than the preferred $90^{\circ}$ discussed in Section 3.2. The circumferential offset of the strain gauge sets causes the two channels to record different values for the bending strain. $M_{B 1}$ and $M_{B 2}$ refer to the two bending channels recording data.

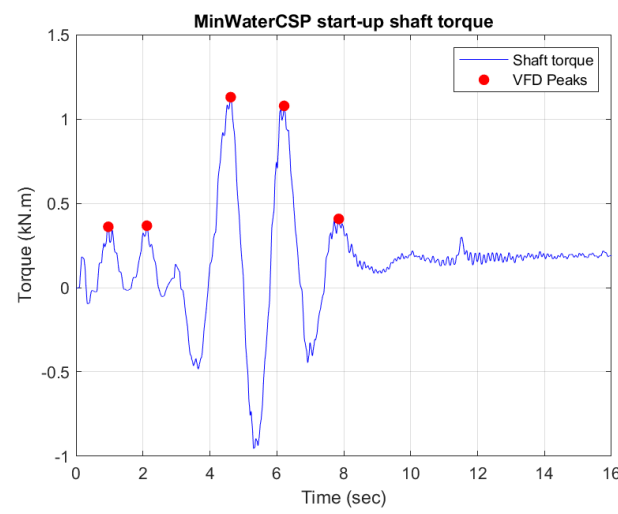

(a)

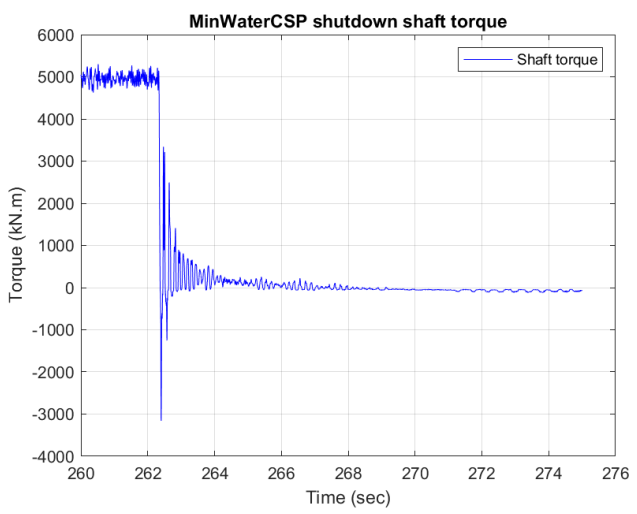

(b)

Figure 10: MinWaterCSP gearbox different shaft torque periods

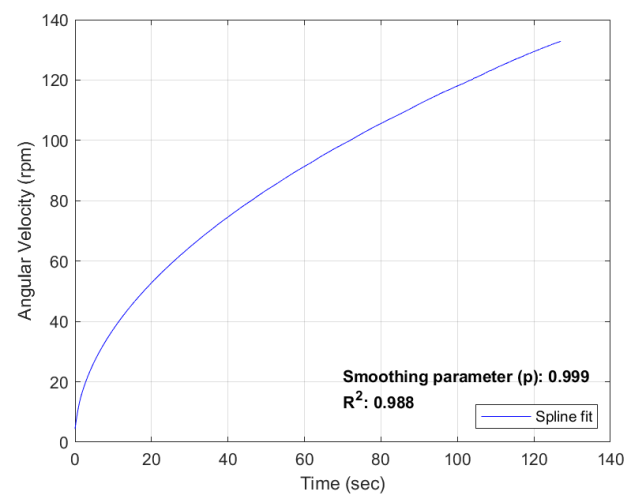

(a) Start-up shaft velocity profile

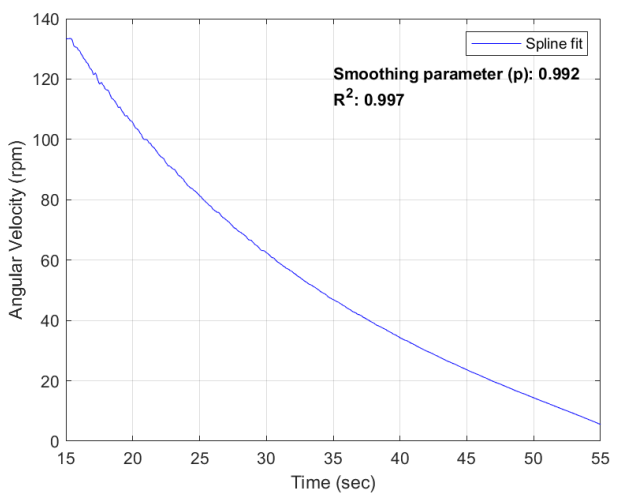

(b) Shutdown shaft velocity profile

Figure 11: MinWaterCSP gearbox different velocity profiles 


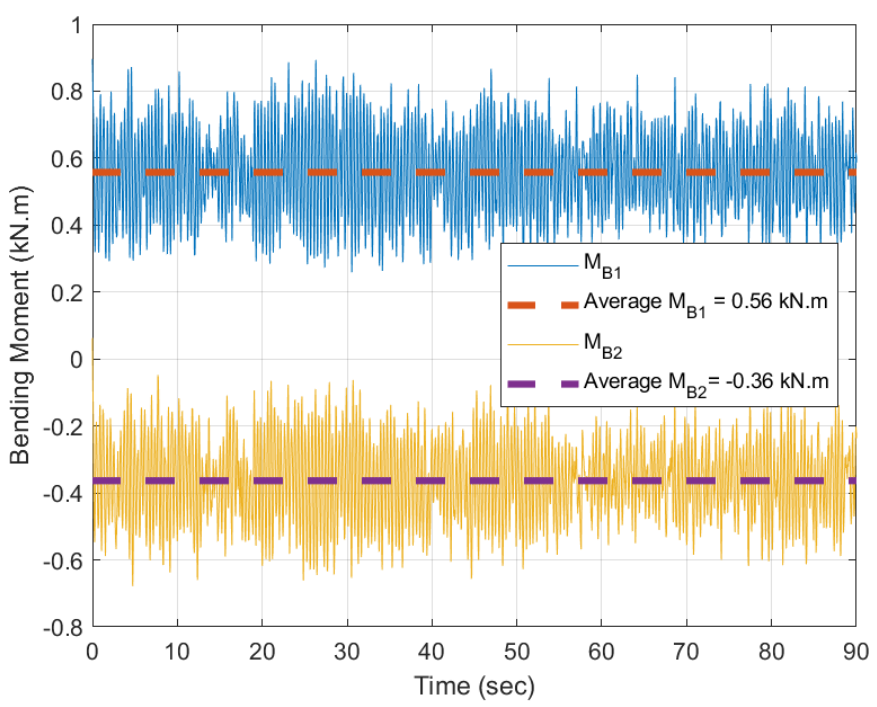

Figure 12: Average bending moments for 90 second period - MinWaterCSP

\subsection{Thermal Power Station Test Sites}

The power station with the DOL starting method is termed power station I and the softstarter controlled induction motor, power station II. The different starting methods are directly compared against each other using the data mentioned in Section 3. From Figure 13, it is possible to compare the different velocity profiles of the DOL and the soft-starter. The DOL takes $\sim 4 \mathrm{~s}$ to reach full speed whereas with this soft-starter it takes approximately $\sim 13 \mathrm{~s}$.

The same procedure implemented in Section 4.1 for the shaft velocity is used here. Smoothing splines are again fitted with the smoothing parameter chosen so to fit the data as best as possible without jeopardising the validity thereof. Both fans were rotating at the start of measurement, hence the angular velocity graphs not starting from zero.

In Figure 14 the low-speed shaft torques are directly compared for the start-up period. The high starting voltage of power station I's induction motor causes the gearbox shaft to experience a torque peak of $62.45 \mathrm{kN} \cdot \mathrm{m}$ which is approximately four times the steady-state value. The soft-starter is able to start the motor at a reduced voltage and the initial torque peak is $14 \%$ of that experienced for a induction motor with a direct-on-line connection.

At power station II, the motor is started with a lower voltage (approximately $30 \%$ ) of the supply voltage and the torque is gradually increased as a result. The excitation period seen between $10 \mathrm{~s}$ and $14 \mathrm{~s}$ is caused by the soft-starter introducing harmonic excitations during start-up [7] as a result of the ratio between the instantaneous supply voltage and the rated supply voltage. In Figure 16a, the calculated bending moment for both channels are shown during steady-state operation for 2 minutes as well as a polar plot in the rotating coordinate system of the shaft. The offset in the data indicates that there is a continuous unbalance force on the shaft caused by the fan during steady-state operation. 


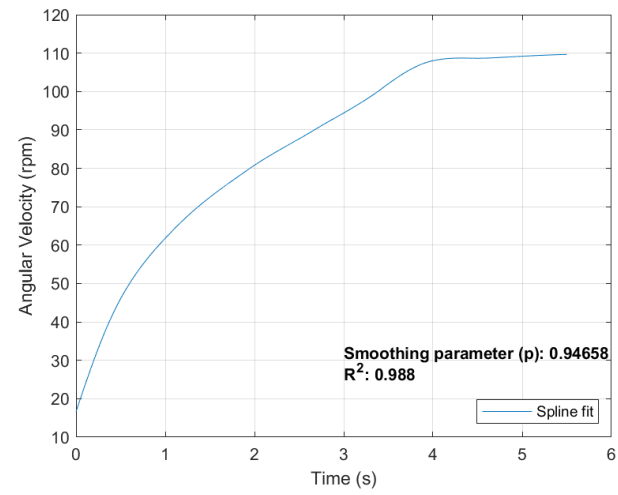

(a) Power station I start-up velocity profile

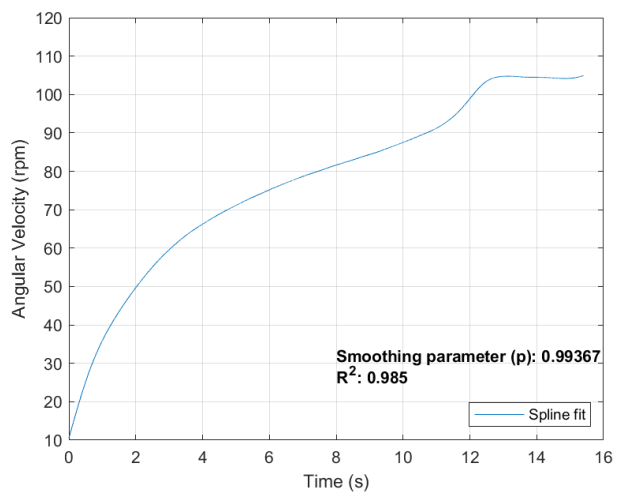

(b) Power station II start-up velocity profile

Figure 13: Comparison of gearbox shaft velocity profiles

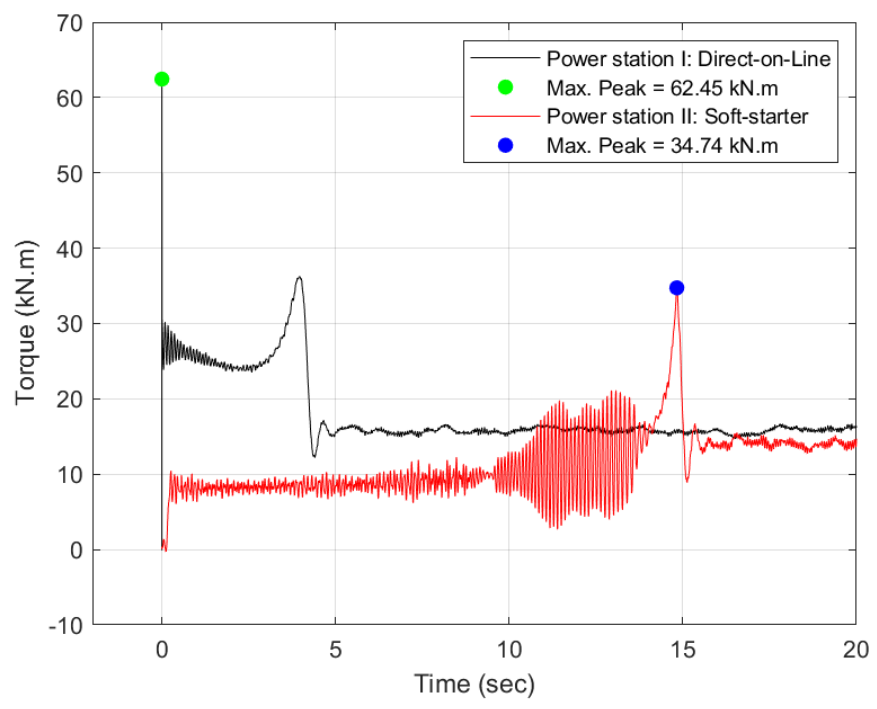

Figure 14: Power station I \& II start-up gearbox shaft torque comparisons 


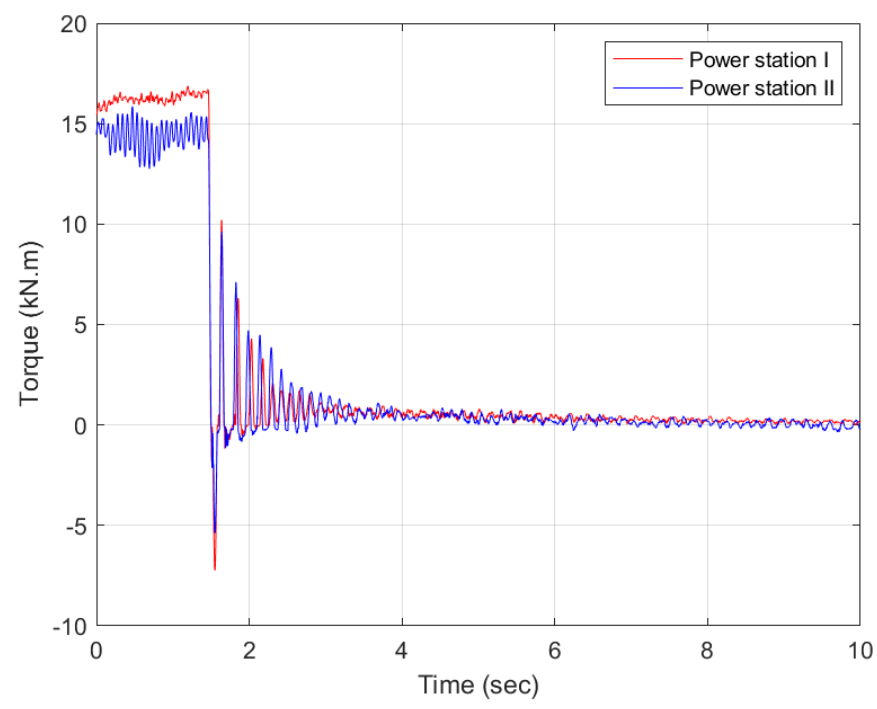

Figure 15: Power station I \& II shutdown gearbox shaft torque comparison
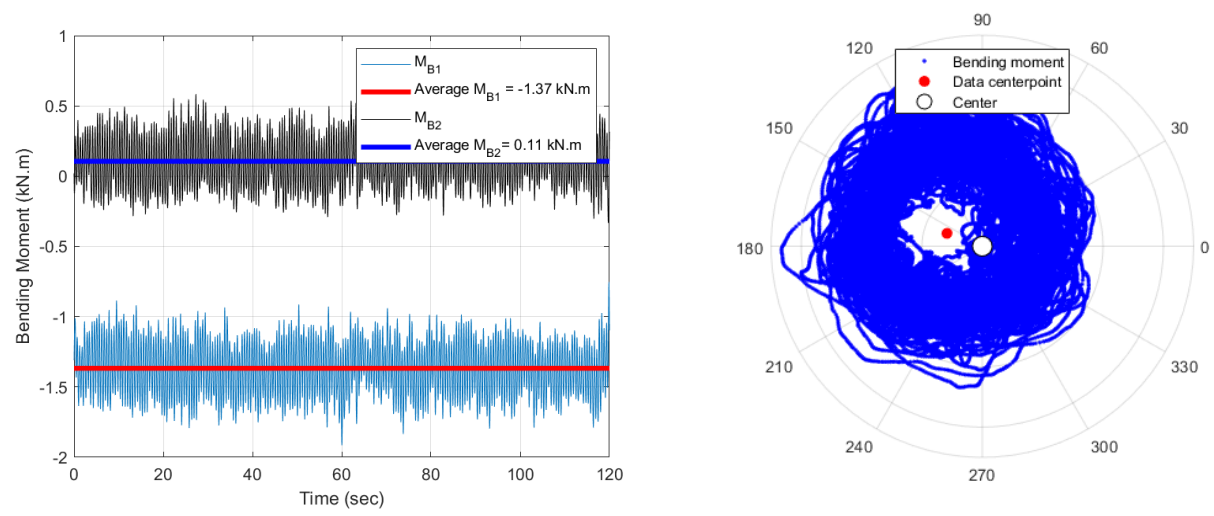

(a) Average bending moment for 2 minutes

(b) Polar plot of absolute bending moment calculated

Figure 16: Power station I bending moments 


\section{Conclusion}

This research set out to take various measurements on three different test sites of an aircooled condenser. The measurements set out in Section 3 were carried out with repeatable results. The data acquisition (DAQ) system was developed by performing a system analysis at the MinWaterCSP facility to determine the measurements that are possible. Thereafter, the correct sensors and equipment were chosen and following test runs.

The average calculated absolute bending moment for power station I is $\sim 2.52 \mathrm{kN} \cdot \mathrm{m}$. This coincides well with that measured by [1] at $\sim 2.8 \mathrm{kN} \cdot \mathrm{m}$ at the same power station. This confirms that the experimental setup used and calibration of the sensors were correctly done. From Sections 4.1 and 4.2 , it can be seen that the velocity profile of power station I has a steaper slope compared to power station II and the MinWaterCSP facility.

Every bending moment recorded follows a particular trend, where the initial value is close to zero and after the start-up phase is over, it oscillates around a constant value. Another difference noticed in Section 4 is the different start-up torque profiles for each test site. The five peaks found in the torque profile of the MinWaterCSP facility cannot be accounted for until the PLC's start-up algorithm is understood. At the time of motor shut down, there is a sudden decrease in shaft torque of $\sim 8 \mathrm{kN} \cdot \mathrm{m}$ as the fan decelerates.

Figure 14 directly compare the two different torque profiles between power stations I and II. Power station I's torque profile is typical for an induction motor with a direct-on-line start. In each case, the shaft torque is gradually increased after the initial peak and settles at the stead-state value after the breakdown torque is reached.

The axial fans tested on at power stations I and II have an inertia of $9501 \mathrm{~kg} \cdot \mathrm{m}^{2}$ and $7962 \mathrm{~kg} \cdot \mathrm{m}^{2}$ respectively. This explains the near exact steady-state torque value for both sites. From Figure 15, one can see a similar profile for the shaft torque to the MinWaterCSP motor, although here a difference of $\sim 20 \mathrm{kN} \cdot \mathrm{m}$ is noted. Another advantage of the soft-starter controller, is the ability to control the stoppage of the induction motor which is evident from the small upward peaks. In the case of power station I, power is cut from the motor and it then decelerates freely.

The lower shaft torque peak and relatively fast starting time of power station II's motor provide a convincing argument for the soft-starter. Since these induction motors at the power stations always run at rated speed, there is little need to install a VFD, which is more expensive. Considering the results found in Section 4 and the cost of installation of each starting method, the soft-starter can be concluded as the best motor controller amongst the different methods evaluated.

\section{References}

[1] C.H.O. Lombard, Analysis Of Gearbox Loads In Large Air Cooled Condensers (2017)

[2] Dr J. Muiyser, Analysis of vibration inducing sources of a large-scale cooling system fan blade (2016)

[3] MinWaterCSP, https://www.minwatercsp.eu/, (2018)

[4] J. Muiyser, Simultaneous measurement of air flow conditions and the resultant blade and gearbox loading at large-scale cooling system fans (2012)

[5] H. Goldschagg, ACC Fan Gearboxes: Eskom's Experience in the Selection and Maintenance of ACC gearboxes (ACCUG Nevada Conference, 2013)

[6] R.J. Drago, The effect of start-up load conditions on gearbox performance and life - Failure analysis and case study (Meeting of the American Gear Manufacturers Association, 2007)

[7] ABB, Softstarter Handbook (2021) 